\title{
Single-stage unity power factor based electronic ballast
}

\author{
ASHISH SHRIVASTAVA* and BHIM SINGH \\ Electrical Engineering Department, Indian Institute of Technology Delhi, New Delhi 110016, India \\ e-mail: rewa.ashish@gmail.com; bhimsingh1956@gmail.com
}

MS received 25 May 2015; revised 2 March 2016; accepted 10 April 2016

\begin{abstract}
This paper deals with the design, modeling, analysis and implementation of unity power factor (UPF) based electronic ballast for a fluorescent lamp (FL). The proposed electronic ballast uses a boost AC-DC converter as a power factor corrector (PFC) to improve the power quality at the input ac mains. In this singlestage UPF based electronic ballast, boost PFC converter and a half bridge series resonant inverter (HBSRI) share a common power switch. Thus one power switch is reduced as compared to the conventional two-stage approach. The design, modeling, analysis and implementation of this topology were carried out in MATLABSimulink environment for a T8 $36 \mathrm{~W}, 220 \mathrm{~V}, 50 \mathrm{~Hz}$ fluorescent lamp. The switching frequency was kept more than the resonant frequency of the inverter, to ensure the zero voltage switching (ZVS) operation of both power switches. This resulted in reduction of high frequency switching losses. The power quality parameters such as displacement power factor (DPF), distortion factor (DF), power factor (PF), crest factor (CF) and total harmonic distortion of ac mains current $\left(\mathrm{THD}_{\mathrm{i}}\right)$ were evaluated to analyze the performance of proposed electronic ballast. Test results on a developed prototype of PFC electronic ballast were included to validate the design and simulated results.
\end{abstract}

Keywords. Power factor corrector (PFC); high switching frequency; series resonant inverter; fluorescent lamp; zero voltage switching (ZVS).

\section{Introduction}

Nowadays industries, hospital, institutes, airports, underground metro railway systems, big multiplexes, underground parking spaces and multi-storied residential complexes use a wide range of discharge lamps with different power ratings and luminaries. All kinds of discharge lamps require sufficient ignition voltage at the time of starting and rated steady state current after the ignition, because they have inherent negative resistance characteristics [1]. Thus they require a magnetic/electronic ballast to control the flow of current after ignition. It is noteworthy that the performance of discharge/fluorescent lamps (FLs) improves with the use of high frequency electronic ballast. The other advantages of using electronic ballast are smaller size, lesser weight and hum, increased efficacy (lumens/ watt) and longer lamp life as compared to the magnetic ballast.

The electronic ballast consists of a diode bridge rectifier (DBR), power factor correction stage and high frequency inversion stage and a proper series resonant circuit. The resonant circuit generates required high ignition voltage at the time of starting and then regulates the lamp current to become sinusoidal. As compared to the magnetic ballast,

*For correspondence which supplies the lamp a line frequency current of $50 / 60 \mathrm{~Hz}$, the electronic ballast provides the lamp $20-100 \mathrm{kHz}$ frequency current using an inverter. Because of the relatively high switching frequency of the electronic ballast, the gas in the discharge tube does not suffer from an appreciable deionization and a sufficient number of electron carriers required for discharge remain after current reversal. Thus, there is no power required to reignite the discharge, which results in 10-20\% increase in luminous flux.

However, electronic ballast also has many limitations. The electronic ballast involves AC-DC conversion; hence, a large amount of current distortion exists into the ac mains. Owing to the small conduction time of rectifier and filter capacitor combination creates distortion in current waveform which is rich in odd harmonics and also has a relatively high crest factor. Another disadvantage of the electronic ballast is the radio frequency interference which is induced by the high switching frequency of the resonant inverter which drives the lamp. Further, this electronic ballast has power quality problems such as low power factor (PF), high crest factor (CF) and high total harmonic distortion $\left(\mathrm{THD}_{\mathrm{i}}\right)$ of ac mains current, which do not meet the requirements of the international regulations such as IEC 61000-3-2 for class $C$ equipments [2].

Due to these limitations of electronic ballast, power factor corrected (PFC) electronic ballast is gaining 
popularity these days. Normally, PFC electronic ballast needs two stages of power conversion. One stage is for acdc power conversion and another stage is for $\mathrm{dc}-\mathrm{ac}$ power conversion. The advantages of the PFC electronic ballast are reduction in ac mains current and its crest factor [2]. However, because of the two power stages, this circuit has low energy conversion efficiency. The other PFC approach is based on the integration of these two power stages into a single-stage converter by sharing one or more switches.

This paper deals with the power factor correction (PFC) in the single-stage electronic ballast. An integration technique has been used by combining the power switch of boost converter with a half bridge resonant inverter using a boost converter operating in continuous conduction mode (CCM) and integrated with series resonant inverter. This method provided almost unity power factor (UPF) with low THD and low crest factor of ac mains current for a wide variation in ac mains supply voltage.

\section{Proposed single stage electronic ballast}

The schematic of proposed electronic ballast is shown in figure 1, which consists of a PFC boost converter integrated with a high frequency series resonant inverter and this combination formed single-stage electronic ballast.

The following considerations were made while analyzing the proposed single-stage electronic ballast:

- The fluorescent lamp was treated as an open circuit before ignition and as a resistor under steady state condition.

- The capacitor $C_{\mathrm{b}}$ was large enough as compared to $C_{\mathrm{p}}$, to ensure its negligible reactance at switching frequency. Moreover, $C_{\mathrm{b}}$ blocked the dc component present in the fundamental component of square input to the inverter.
- The de link capacitor $C_{\mathrm{o}}$ must be large enough to ensure the CCM operation of boost converter.

- The switching frequency was selected much higher than the ac mains frequency, thus input voltage could be considered as constant over a switching cycle.

- Quality factor should be high enough to ensure proper ignition voltage at start up and sinusoidal load current.

- The filament resistances were neglected as compared to the lamp resistance.

PFC boost converter nearly achieved UPF at input ac mains. Simultaneously, the resonant inverter provided sufficient ignition voltage and provided constant lamp current at higher frequency. The quasi-half bridge inverter produced a square wave voltage which was fed to the load through an LC network which filters out the higher order harmonic components in the square wave. As the harmonics of the square wave are attenuated by the LC network, an analysis is carried out using only the fundamental component of the square wave.

The switching frequency of the resonant inverter was kept more than the resonance frequency of the inverter to ensure zero voltage switching (ZVS), which reduced the switching losses and increases the overall efficiency of the system [3-6].

\section{Operating modes of single stage electronic ballast}

The operating modes of proposed single-stage electronic ballast are shown in figure $2 \mathrm{a}-\mathrm{d}$ along with the waveform in figure 2e. The sinusoidal input voltage was considered as constant in each switching cycle, since the switching frequency is much higher than the ac mains power frequency. The circuit operation is explained using modes I-IV over one switching cycle:

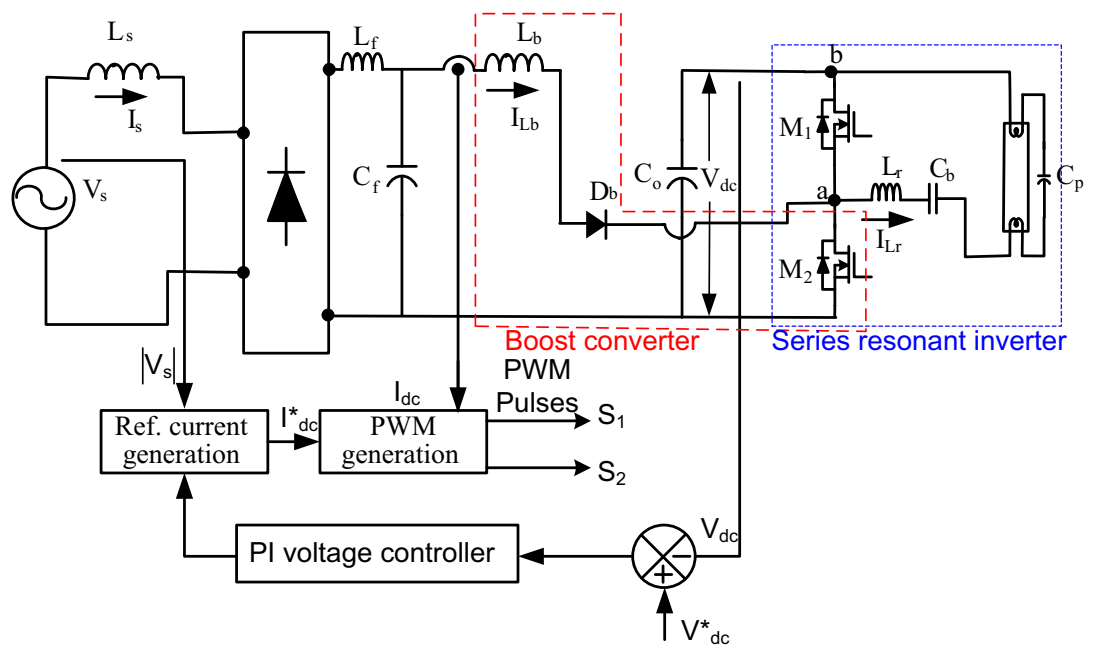

Figure 1. Proposed single-stage electronic ballast. 
(a)
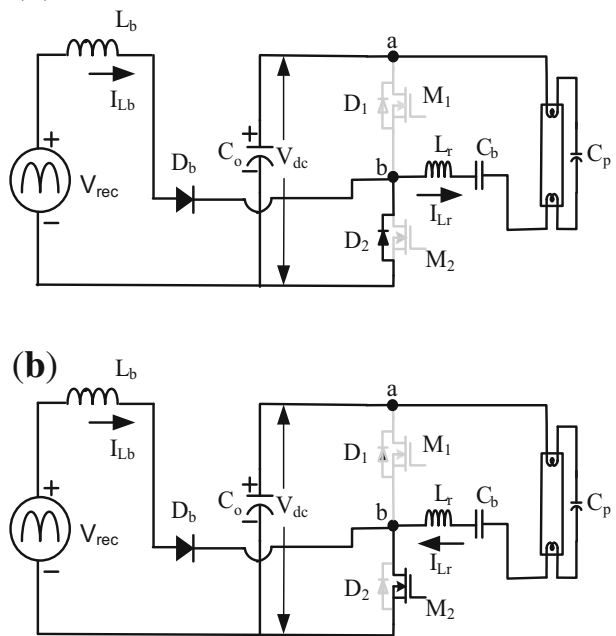

(c)

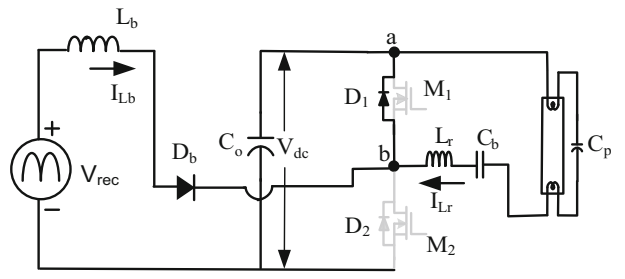

(d)

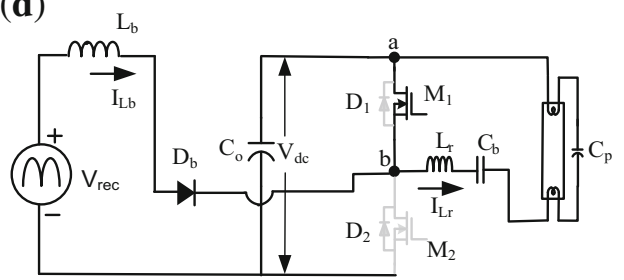

(e)

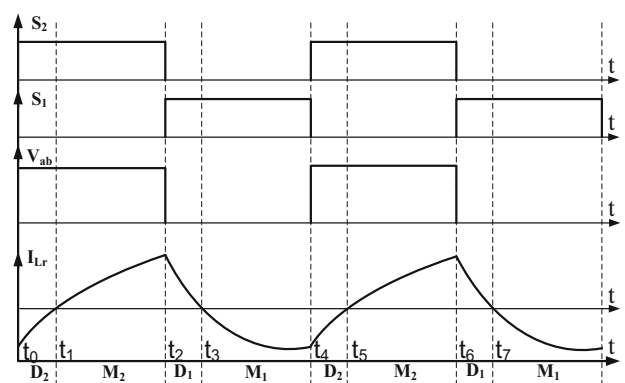

Figure 2. (a) Mode I, (b) mode II, (c) mode III, (d) mode IV, and (e) theoretical waveforms of resonant inverter stage of proposed electronic ballast.

\section{Mode I $\left(t_{0} \leq t \leq t_{1}\right)$}

At time $t_{0}$, initially intrinsic diode $\mathrm{D}_{2}$ (shown in figure 2a) starts conducting and maintaing the dc link voltage by charging the capacitor gradually. The rectified input voltage (after the LC filter) is applied to the boost inductor $\left(L_{\mathrm{b}}\right)$, which forms a close path with the dc link capacitor. Thus the boost inductor current increases linearly up to time $t_{1}$. During this interval the gate pulse $\left(\mathrm{S}_{2}\right)$ is also applied to active power switch $\mathrm{M}_{2}$. In this mode, the path of two currents is shown in figure $2 \mathrm{a}$ and given by loop- 1 and loop-2.

$$
\begin{aligned}
& \text { Loop-1: } \mathrm{V}_{\text {rec }}(+) \rightarrow \mathrm{L}_{\mathrm{b}} \rightarrow \mathrm{D}_{\mathrm{b}} \rightarrow \mathrm{L}_{\mathrm{r}} \rightarrow \mathrm{C}_{\mathrm{b}} \\
& \quad \rightarrow\left(\mathrm{R}_{\text {lamp }}|| \mathrm{C}_{\mathrm{P}}\right) \rightarrow \mathrm{C}_{\mathrm{o}} \rightarrow \mathrm{V}_{\text {rec }}(-) \\
& \text { Loop-2: } \mathrm{C}_{\mathrm{o}}(-) \rightarrow \mathrm{D}_{2} \rightarrow \mathrm{L}_{\mathrm{r}} \rightarrow \mathrm{C}_{\mathrm{b}} \\
& \quad \rightarrow\left(\mathrm{R}_{\text {lamp }}|| \mathrm{C}_{\mathrm{P}}\right) \rightarrow \mathrm{C}_{\mathrm{o}}(+)
\end{aligned}
$$

Mode II $\left(t_{1} \leq t \leq t_{2}\right)$

At time $t_{1}$, the resonant inductor current further increases linearly up to time $t_{2}$, since only the impedance of inductor offers the opposition for the flow of current. Because of already conduction of intrinsic diode $\mathrm{D}_{2}$, the MOSFET $\mathrm{M}_{2}$ is turned on at ZVS. In this duration, dc link capacitor is lost some of its charge. In this mode, the path of two currents is shown in figure $2 \mathrm{~b}$ and given by loop- 1 and loop- 2 .

$$
\begin{aligned}
& \text { Loop-1 }: \mathrm{V}_{\text {rec }}(+) \rightarrow \mathrm{L}_{\mathrm{b}} \rightarrow \mathrm{D}_{\mathrm{b}} \rightarrow \mathrm{M}_{2} \rightarrow \mathrm{V}_{\text {rec }}(-) \\
& \text { Loop-2: } \mathrm{C}_{\mathrm{o}}(+) \rightarrow\left(\mathrm{R}_{\text {lamp }} \| \mathrm{C}_{\mathrm{P}}\right) \rightarrow \mathrm{C}_{\mathrm{b}} \rightarrow \mathrm{L}_{\mathrm{r}} \rightarrow \mathrm{M}_{2} \rightarrow \mathrm{C}_{\mathrm{o}}(-)
\end{aligned}
$$

Mode III $\left(t_{2} \leq t \leq t_{3}\right)$

MOSFET $\mathrm{M}_{2}$ is turned off at time tand given by loop- 1 and loop and the resonant current shifts from MOSFET $\mathrm{M}_{2}$ to intrinsic diode $\mathrm{D}_{1}$, thus due to series resonating phenomenon of the circuit resonant current still flows in the same direction. During this mode of operation, the boost inductor current decreases linearly since effective voltage across the inductor is $\left(V_{\mathrm{rec}}-V_{\mathrm{dc}}\right)$. In this duration the gate pulse $\left(S_{1}\right)$ is also applied to active power switch $M_{1}$. In this mode, the path of two currents is shown in figure $2 \mathrm{c}$ and given by loop-1 and loop- 2 . 
Loop-1: $\mathrm{V}_{\text {rec }}(+) \rightarrow \mathrm{L}_{\mathrm{b}} \rightarrow \mathrm{D}_{\mathrm{b}} \rightarrow \mathrm{D}_{1} \rightarrow \mathrm{C}_{\mathrm{o}} \rightarrow \mathrm{V}_{\text {rec }}(-)$

Loop-2: $\mathrm{D}_{1} \rightarrow\left(\mathrm{R}_{\text {lamp }} \| \mathrm{C}_{\mathrm{P}}\right) \rightarrow \mathrm{C}_{\mathrm{b}} \rightarrow \mathrm{L}_{\mathrm{r}} \rightarrow \mathrm{D}_{1}$

\section{Mode IV $\left(t_{3} \leq t \leq t_{4}\right)$}

At time $t_{3}$, the MOSFET $\mathrm{M}_{1}$ is turned on at ZVS, since in earlier mode of operation intrinsic diode $\mathrm{D}_{1}$ was conducting, which ensures the zero voltage transition of the switch. Thus the direction of resonant current changes from positive to negative as shown in figure $2 \mathrm{e}$. This mode completes at $t_{4}$ and then modes I-IV repeat for the new switching cycle. In this mode, the path of two currents is shown in figure $2 \mathrm{~d}$ and given by loop- 1 and loop- 2 .

$$
\begin{aligned}
\text { Loop-1 } & \mathrm{V}_{\mathrm{rec}}(+) \rightarrow \mathrm{L}_{\mathrm{b}} \rightarrow \mathrm{D}_{\mathrm{b}} \rightarrow \mathrm{L}_{\mathrm{r}} \rightarrow \mathrm{C}_{\mathrm{b}} \rightarrow\left(\mathrm{R}_{\text {lamp }} \| \mathrm{C}_{\mathrm{P}}\right) \\
& \rightarrow \mathrm{C}_{\mathrm{o}} \rightarrow \mathrm{V}_{\mathrm{rec}}(-)
\end{aligned}
$$

Loop-2 $: \mathrm{M}_{1} \rightarrow \mathrm{L}_{\mathrm{r}} \rightarrow \mathrm{C}_{\mathrm{b}} \rightarrow\left(\mathrm{R}_{\text {lamp }} \| \mathrm{C}_{\mathrm{P}}\right) \rightarrow \mathrm{M}_{1}$

It is clear from the fact that prior to the conduction of both power switches, their intrinsic diodes conduct first, hence both MOSFETs $\left(\mathrm{M}_{1}\right.$ and $\left.\mathrm{M}_{2}\right)$ are operating at zero voltage switching (ZVS) over a switching cycle. Moreover, the resonant current also lags behind the fundamental component of inverter input voltage $\left(V_{\mathrm{ab}}\right)$, which is also a basic guideline to turn-on the power switches at ZVS. To ensure the lagging nature of resonant inverter circuit, the switching frequency has kept four times of the resonant frequency of the inverter (i.e. $f_{\mathrm{s}}=4 f_{\mathrm{r}}$ ). Important theoretical waveforms of series resonant inverter are given in figure $2 \mathrm{e}$.

\section{Design and analysis of single stage electronic ballast}

The design procedure of the components of PFC boost converter and the series resonant inverter are given as follows $[7,8]$.

\subsection{Design of boost inductor}

The design value of a boost inductor can be calculated by using the following equations. The duty ratio, $D$ is expressed in terms of dc inverse voltage gain as

$$
D=1-\alpha,
$$

where $\alpha$ is defined as

$$
\alpha=\frac{V_{\mathrm{sm}}}{V_{\mathrm{dc}}} .
$$

The value of boost inductor is given in Eq. (8) as

$$
L_{\mathrm{b}}=\left(\frac{V_{\mathrm{sm}}}{\omega_{\text {switching }} \cdot P_{\mathrm{o}}}\right) \cdot \frac{\left(1-\alpha^{2}\right) \cdot Y(\alpha)}{\alpha}
$$

where the coefficient $Y(\alpha)$ is defined as

$$
Y(\alpha)=-2-\frac{\pi}{\alpha}+\frac{2}{\alpha \sqrt{1-\alpha^{2}}}\left\{\frac{\pi}{2}+\tan ^{-1}\left(\frac{\alpha}{\sqrt{1-\alpha^{2}}}\right)\right\} .
$$

The dc link capacitor $\left(C_{\mathrm{o}}\right)$ should have enough capacitance to maintain the constant voltage with less voltage ripple and should provide continuous load current. It can be estimated as

$$
C_{0} \geq \frac{V_{\mathrm{o}}}{4 \pi f_{\mathrm{L}} R_{\mathrm{lamp}} \Delta V_{\mathrm{co}}} .
$$

where $D$ is duty ratio, $\alpha$ is dc inverse voltage gain, $V_{\mathrm{sm}}$ is peak value of the input voltage, $V_{\mathrm{dc}}$ is dc link voltage, $P_{\mathrm{o}}$ is rated output power of fluorescent lamp, $f_{\mathrm{s}}$ is switching frequency, $f_{\mathrm{L}}$ is power frequency, $R_{\text {lamp }}$ is lamp resistance under steady state condition, and $\Delta V_{\text {co }}$ is the ripple voltage of the dc link capacitor.

\subsection{Design of series resonant inverter}

The equivalent circuit of the series resonant inverter (SRI) under the steady-state operation of the fluorescent lamp is shown in figure 3 . In the equivalent circuit $L_{\mathrm{r}}, C_{\mathrm{b}}$ and $C_{\mathrm{p}}$ are the resonant parameters and $R_{\text {lamp }}$ is the resistance of the fluorescent lamp. The capacitor $C_{\mathrm{b}}$ is used to block the dc component present in the square wave applied to the resonant inverter otherwise they can distort the lamp current.

At the time of starting, high voltage is required to ionize the gas present inside the lamp. Thus the series resonant inverter is designed such that during starting, the resonance frequency is equal to the switching frequency to insure high voltage generation across the lamp electrodes. Before the starting of the lamp, resonant circuit consists of $L_{\mathrm{r}}, C_{\mathrm{b}}$ and $C_{\mathrm{p}}$. After the ignition, the switching frequency is selected higher than the resonance frequency to achieve ZVS at turnon transition of both the active switches (i.e. $M_{1}$ and $M_{2}$ ).

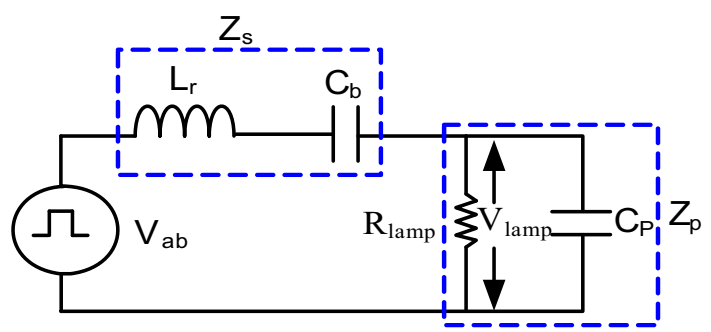

Figure 3. Series resonant inverter (SRI) equivalent circuit. 


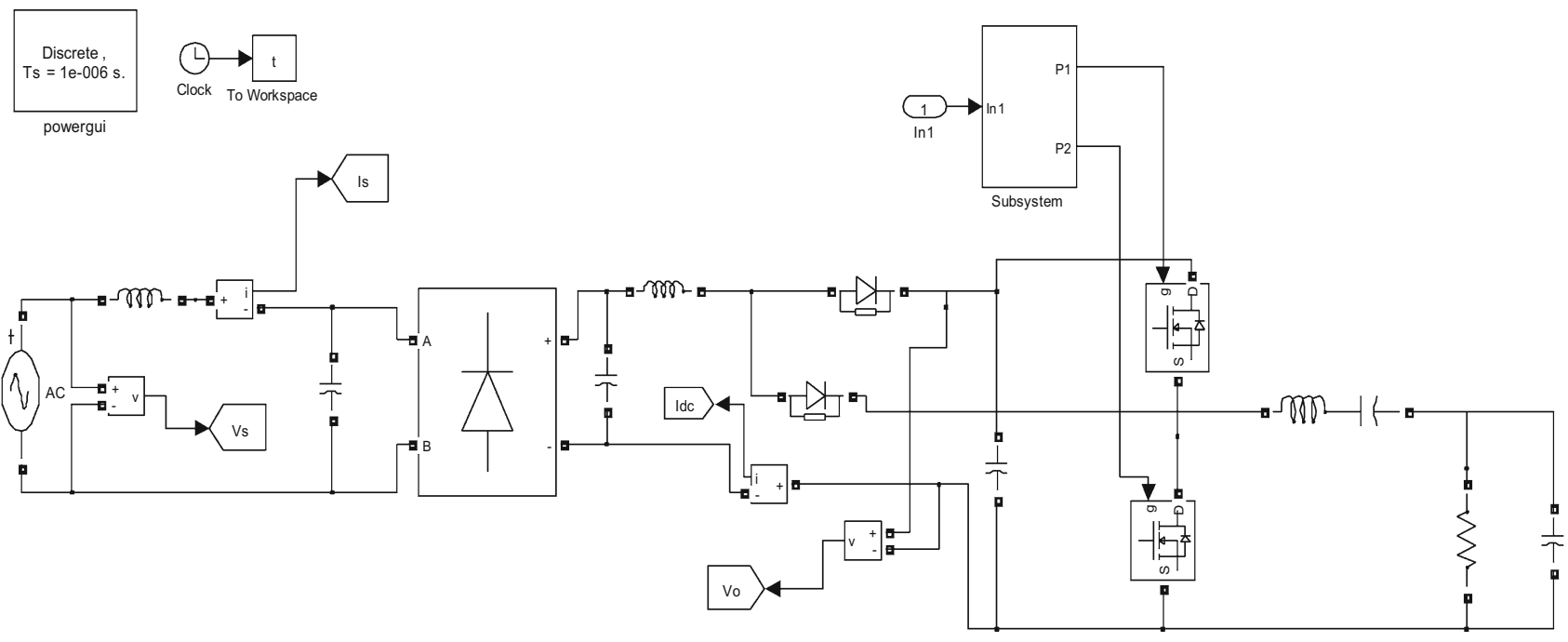

Figure 4. MATLAB model of proposed single stage electronic ballast.

By applying the voltage division rule (figure 3), the ratio of rated lamp voltage $\left(V_{\text {lamp }}\right)$ and the fundamental component of input square voltage $\left(V_{\mathrm{ab}}\right)$ is given as [3],

$\frac{V_{\text {lamp }}(j \omega)}{V_{\mathrm{ab}}(j \omega)}=\frac{1}{\left[1+\left(C_{\mathrm{P}} / C_{\mathrm{b}}\right)-\omega^{2} L_{\mathrm{r}} C_{\mathrm{p}}+j\left(\omega L_{\mathrm{r}} / R\right)-(j / \omega C R)\right]}$

Now substituting, the quality factor $\vec{Q}_{\mathrm{s}}=\left(\omega_{\mathrm{s}} L_{\mathrm{r}} / R_{\text {lamp }}\right)$, the frequency ratio $x=\left(\omega_{\mathrm{r}} / \omega_{\mathrm{s}}\right)$ and the resonance frequency after ignition $f_{\mathrm{r}}=\left(1 / \sqrt{L_{\mathrm{r}} C_{\mathrm{b}}}\right)$ in the above equation, then the results are given as

$$
\left|\frac{V_{\text {lamp }}}{V_{\mathrm{ab}}}\right|=\frac{1}{\sqrt{\left[1+\left(C_{\mathrm{P}} / C_{\mathrm{b}}\right)\left(1-x^{2}\right)^{2}+Q_{\mathrm{s}}\left(x-\frac{1}{x}\right)^{2}\right]}}
$$

Under steady state condition, the resistance of fluorescent lamp is expressed as

$$
R_{\text {lamp }}=V_{\text {lamp }}^{2} / P_{\text {lamp }}
$$

The parallel resonant capacitor is defined as

$$
C_{\mathrm{p}}=\frac{C_{\mathrm{b}}}{(1 / x)^{2}-1}
$$

The series resonant inductor is given as

$$
L_{\mathrm{r}}=\frac{1}{\left(\frac{C_{\mathrm{b}} C_{\mathrm{p}}}{C_{\mathrm{b}}+C_{\mathrm{p}}}\right) \omega_{\mathrm{s}}^{2}}
$$

where $V_{\text {lamp }}$ is the rated lamp voltage, $V_{\mathrm{ab}}$ is the fundamental component of square voltage, $R_{\text {lamp }}$ is the lamp resistance under steady state condition, $\omega_{\mathrm{s}}$ is the angular switching frequency, $C_{\mathrm{b}}$ is blocking capacitor, $C_{\mathrm{p}}$ is parallel resonant capacitor and $L_{\mathrm{r}}$ is the series resonant inductor.

\section{Matlab model of proposed single stage electronic ballast}

As shown in figure 4 the proposed PFC boost converter based single-stage electronic ballast is modeled in MATLAB/Simulink environment, in which fluorescent lamp is considered as a resistor at high frequency $(40 \mathrm{kHz})$.

In proposed single stage electronic ballast topology, current multiplier approach is used with a proportional integral (PI) controller for operating the boost converter in continuous conduction mode (CCM). The designed values of the boost inductor and series resonant inverter components have been optimized to obtain improved power quality at the ac mains. These component values are given in Appendix along with the PI controller and other circuit parameters.

\section{Results and discussion}

The modeling and simulation of the proposed single-stage electronic ballast is carried out to validate the proposed design of an electronic ballast which has low crest factor, high power factor (HPF) and low THD of ac mains current. The dc link voltage is maintained constant at $400 \mathrm{~V}$, for the wide variations of input voltage from $170 \mathrm{~V}$ to 270 V. Figures 5, 6, 7, 8, 9, 10, 11, 12, 13, 14, 15, 16, 17, 18 and 19 show simulated results which are discussed as follows. 

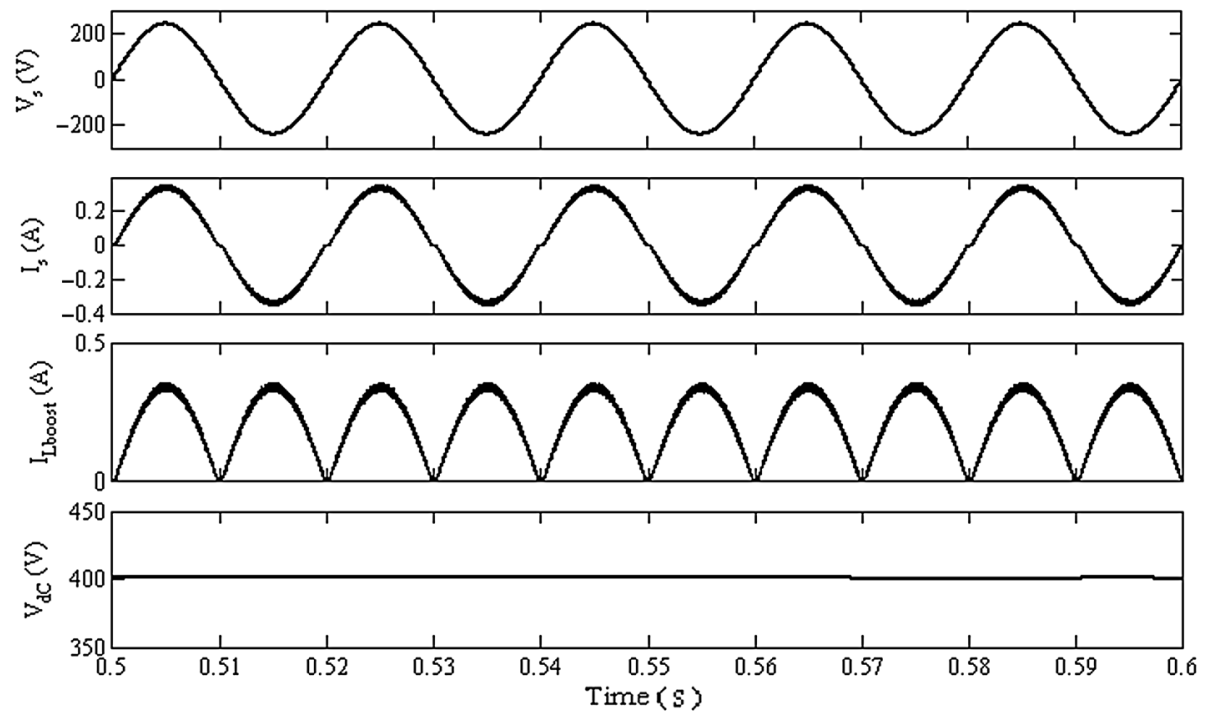

Figure 5. Performance of proposed electronic ballast in terms of source voltage $\left(V_{\mathrm{s}}\right)$, source current $\left(I_{\mathrm{s}}\right)$, boost inductor current $\left(I_{\text {Lboost }}\right)$ and de link voltage $\left(V_{\mathrm{dc}}\right)$ at $170 \mathrm{~V}$.

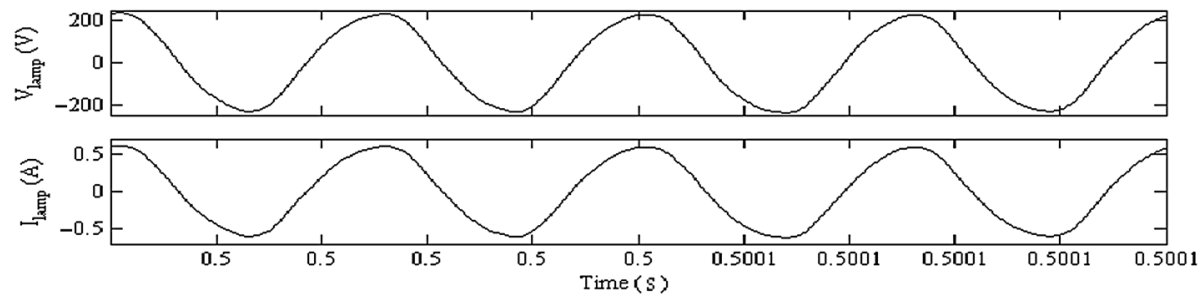

Figure 6. Performance of proposed electronic ballast in terms of lamp voltage $\left(V_{\text {lamp }}\right)$ and lamp current $\left(I_{\text {lamp }}\right)$ at $170 \mathrm{~V}$.
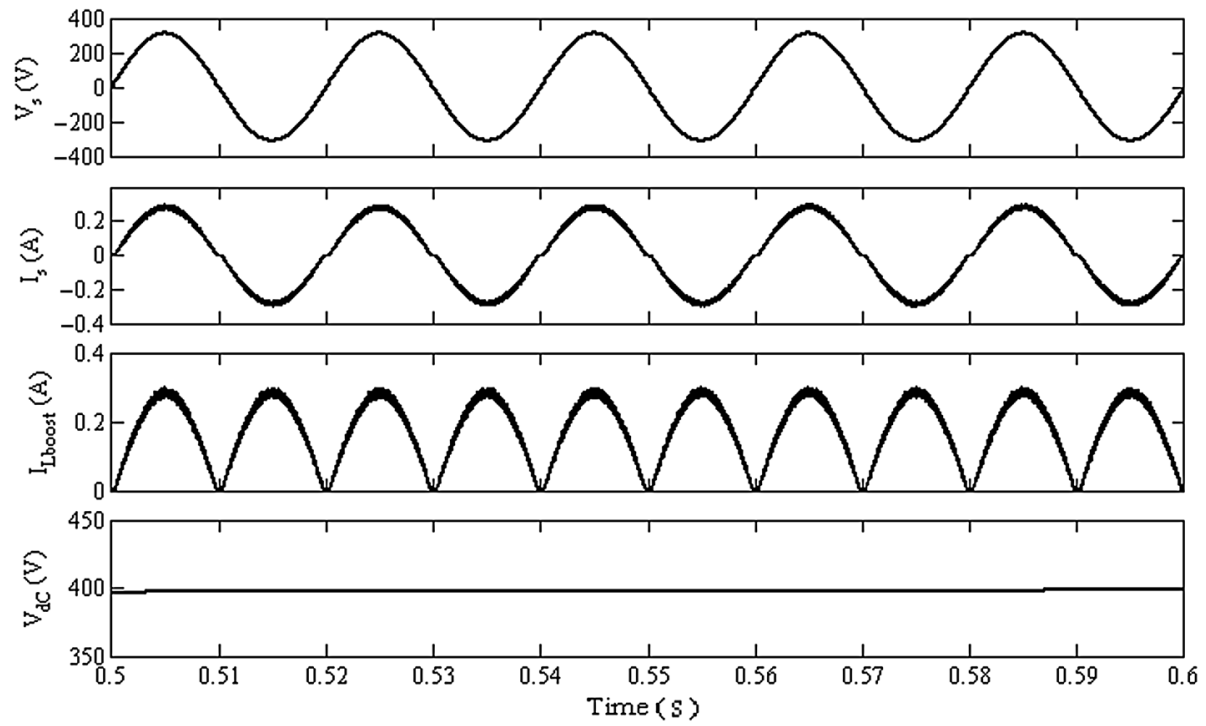

Figure 7. Performance of proposed electronic ballast in terms of source voltage $\left(V_{\mathrm{s}}\right)$, source current $\left(I_{\mathrm{s}}\right)$, boost inductor current $\left(I_{\text {Lboost }}\right)$ and dc link voltage $\left(V_{\mathrm{dc}}\right)$ at $220 \mathrm{~V}$. 

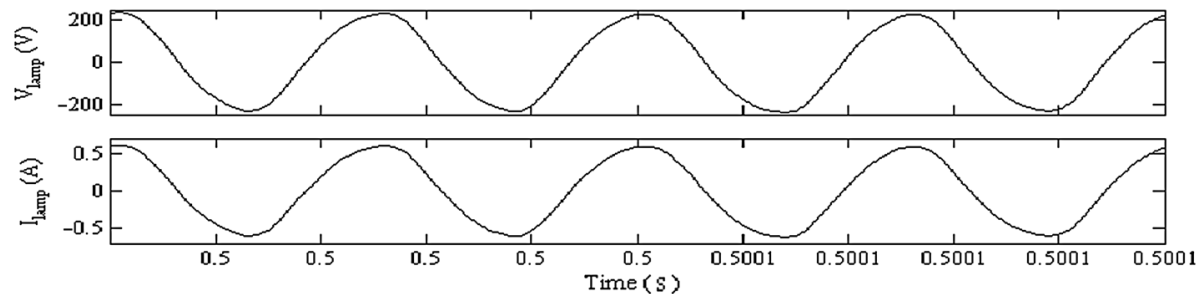

Figure 8. Performance of proposed electronic ballast in terms of lamp voltage $\left(V_{\text {lamp }}\right)$ and lamp current $\left(I_{\text {lamp }}\right)$ at $220 \mathrm{~V}$.
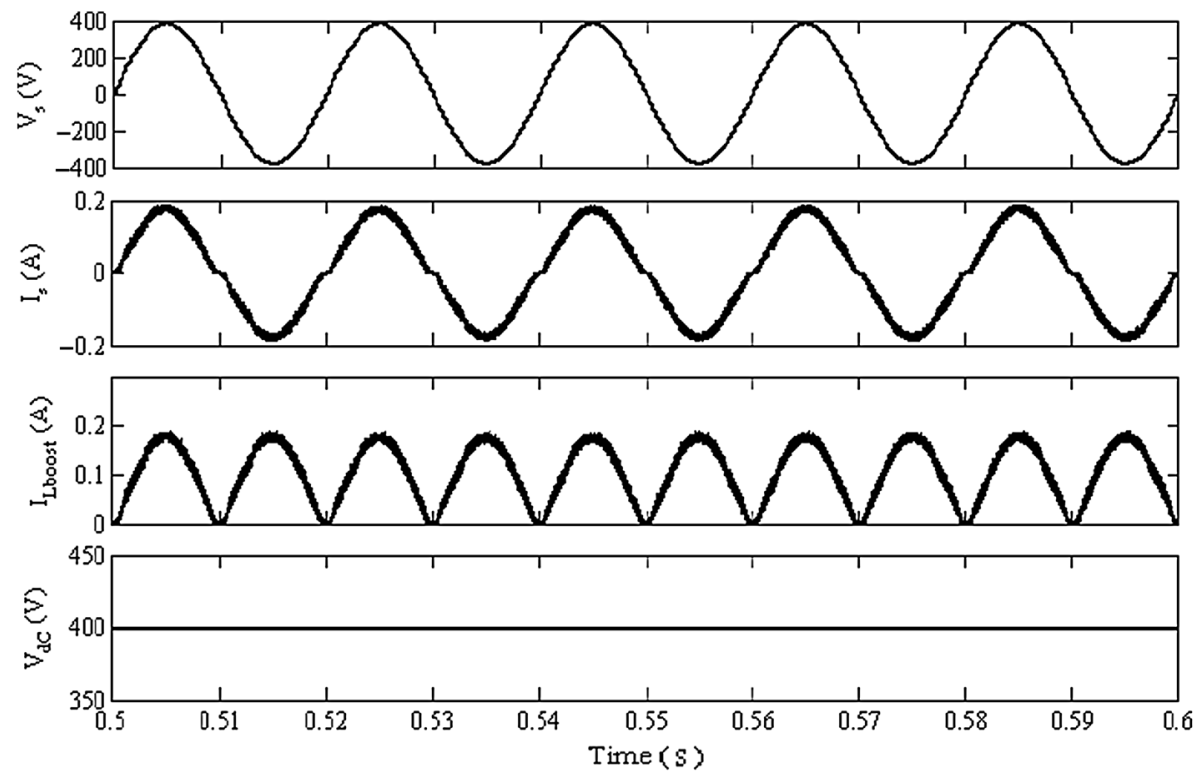

Figure 9. Performance of proposed electronic ballast in terms of source voltage $\left(V_{\mathrm{s}}\right)$, source current $\left(I_{\mathrm{s}}\right)$, boost inductor current $\left(I_{\mathrm{Lboost}}\right)$ and dc link voltage $\left(V_{\mathrm{dc}}\right)$ at $270 \mathrm{~V}$.

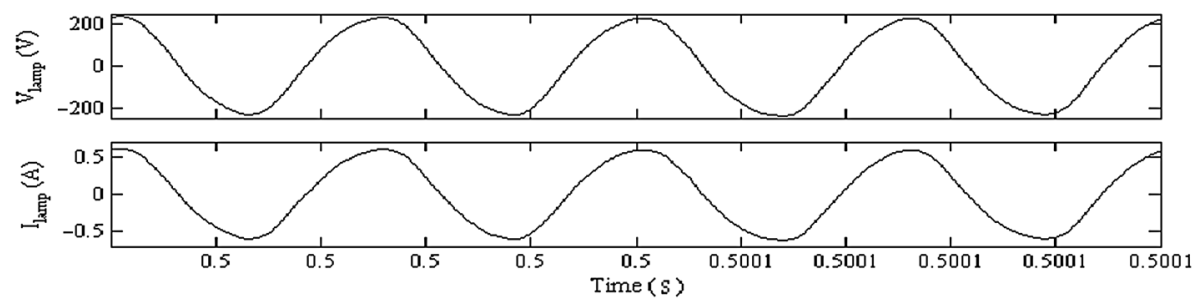

Figure 10. Performance of proposed electronic ballast in terms of lamp voltage $\left(V_{\text {lamp }}\right)$ and lamp current $\left(I_{\text {lamp }}\right)$ at $270 \mathrm{~V}$.

\subsection{Simulation results}

Under steady state operation, the input voltage $\left(V_{\mathrm{s}}\right)$, input current $\left(I_{\mathrm{s}}\right)$, boost inductor current $\left(I_{\text {Lboost }}\right)$ and dc link voltage $\left(V_{\mathrm{dc}}\right)$ at ac mains voltage of $170 \mathrm{~V}, 220 \mathrm{~V}$ and $270 \mathrm{~V}$ are shown in figures 5,7 , and 9 . Under steady state operation, the lamp voltage $\left(V_{\text {lamp }}\right)$ and lamp current $\left(I_{\text {lamp }}\right)$ at ac mains voltage of $170 \mathrm{~V}, 220 \mathrm{~V}$ and $270 \mathrm{~V}$ are shown in figures 6,8 and 10 .

The main advantage of the proposed ballast is low switching losses by sharing one active switch between boost 

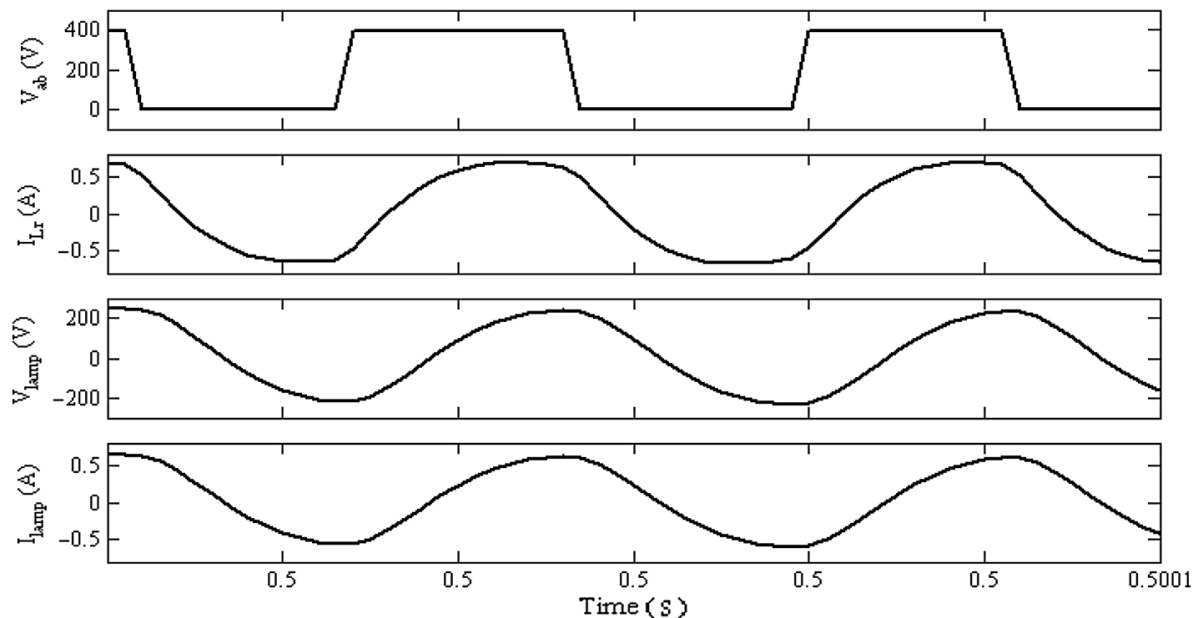

Figure 11. Performance of proposed electronic ballast in terms of resonant inverter voltage $\left(V_{\mathrm{ab}}\right)$, resonant inductor current $\left(I_{\mathrm{Lr}}\right)$, lamp voltage $\left(V_{\text {lamp }}\right)$ and lamp current $\left(I_{\text {lamp }}\right)$ at $170 \mathrm{~V}$.
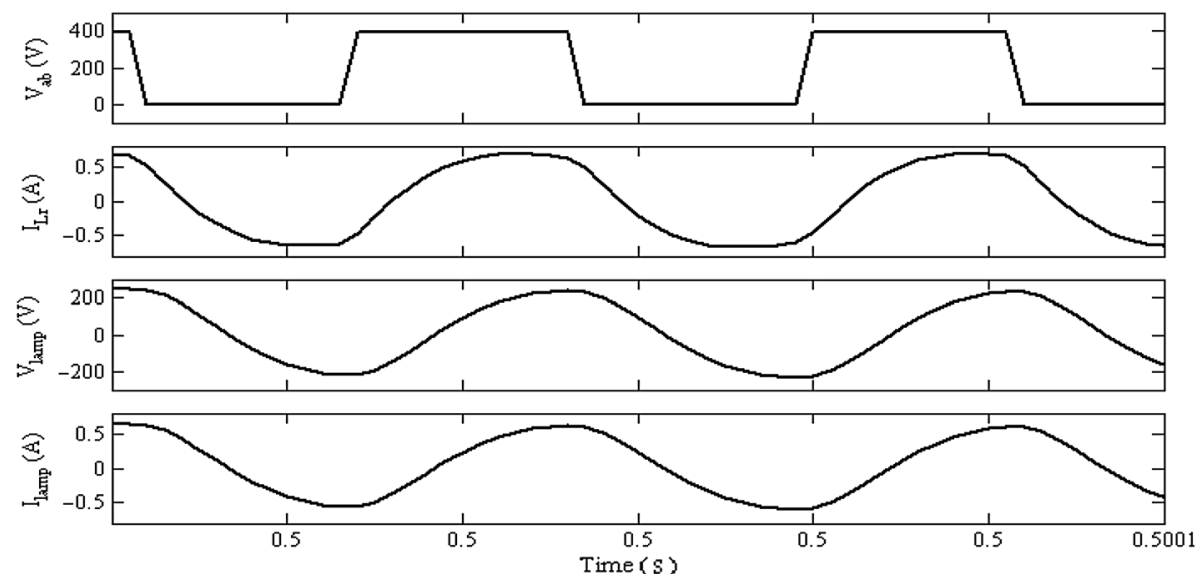

Figure 12. Performance of proposed electronic ballast in terms of resonant inverter voltage $\left(V_{\mathrm{ab}}\right)$, resonant inductor current $\left(I_{\mathrm{Lr}}\right)$, lamp voltage $\left(V_{\text {lamp }}\right)$ and lamp current $\left(I_{\text {lamp }}\right)$ at $220 \mathrm{~V}$.
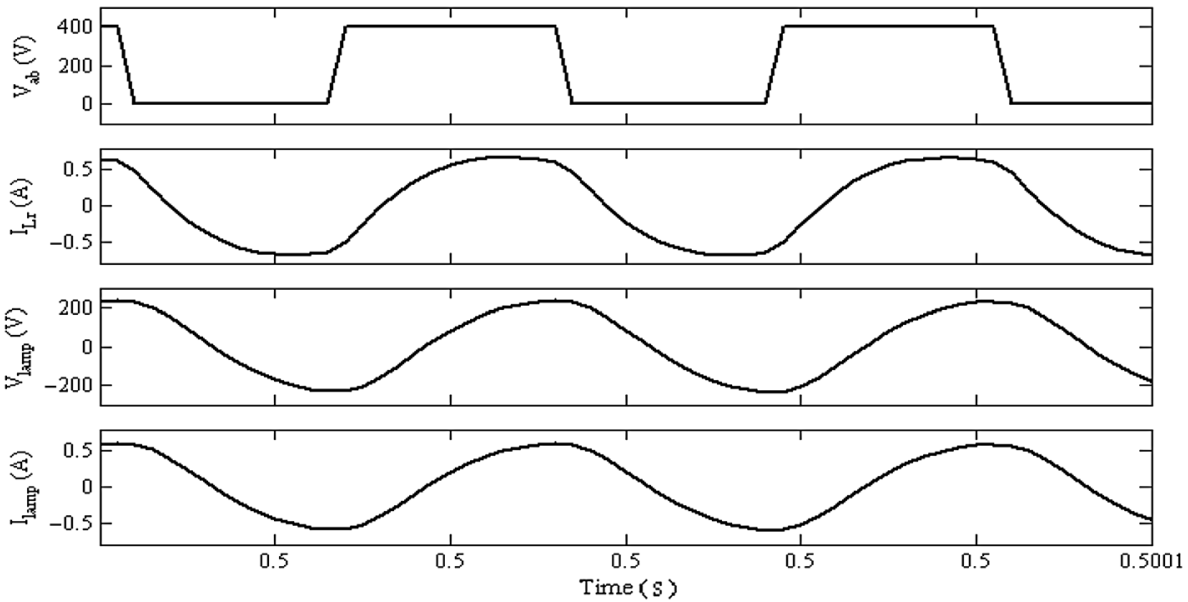

Figure 13. Performance of proposed electronic ballast in terms of resonant inverter voltage $\left(V_{\mathrm{ab}}\right)$, resonant inductor current $\left(I_{\mathrm{Lr}}\right)$, lamp voltage $\left(V_{\text {lamp }}\right)$ and lamp current $\left(I_{\text {lamp }}\right)$ at $270 \mathrm{~V}$. 


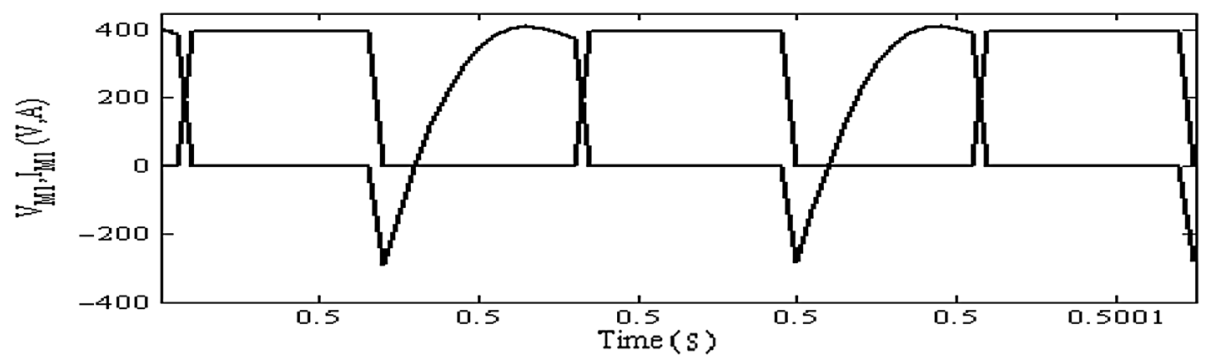

Figure 14. Performance of proposed electronic ballast in terms of first switch voltage $\left(V_{\mathrm{M} 1}\right)$ and switch current $\left(600 \mathrm{I}_{\mathrm{M} 1}\right)$ at $220 \mathrm{~V}$.

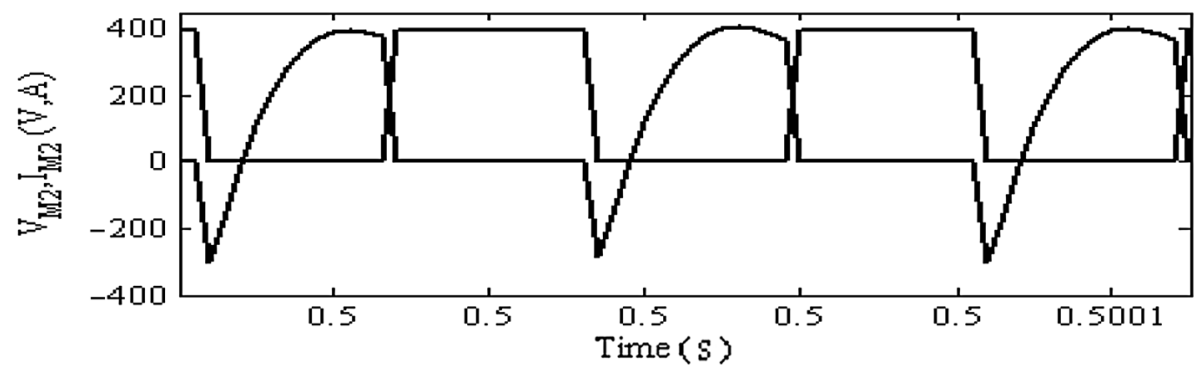

Figure 15. Performance of proposed electronic ballast in terms of second switch voltage $\left(V_{\mathrm{M} 2}\right)$ and switch current $\left(600 \mathrm{I}_{\mathrm{M} 2}\right)$, at $220 \mathrm{~V}$.

(a)
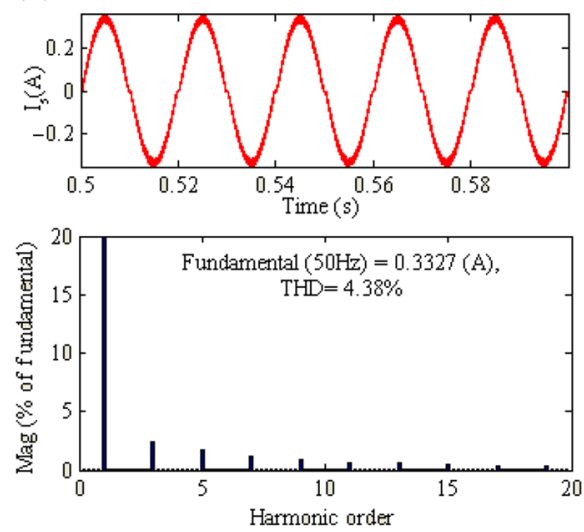

(b)
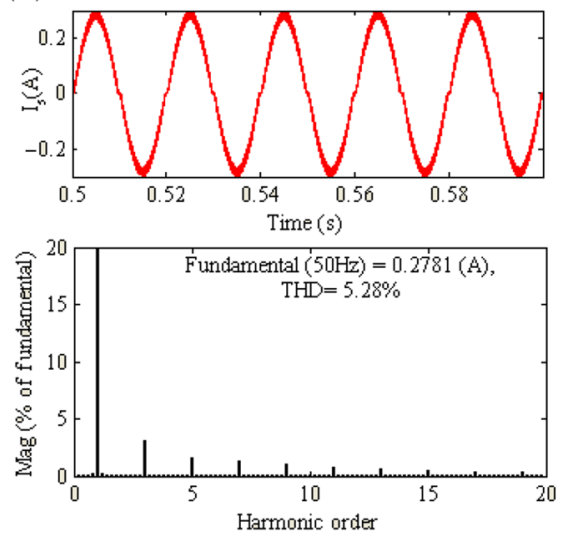

Figure 16. Input current waveform and its harmonic spectra at ac mains voltage of (a) $170 \mathrm{~V}$ and (b) $220 \mathrm{~V}$.

PFC converter and half-bridge inverter, which also reduces the cost. With the input ac mains voltage variations, there is a negligible variation in the rated lamp voltage $(110 \mathrm{~V})$ and rated lamp current $(0.2836 \mathrm{~A})$ which have been given in table 1 . The output waveforms such as resonant inverter voltage, resonant inductor current, lamp voltage and lamp current waveforms are shown in figures $11-13$ for ac mains voltage of $170 \mathrm{~V}, 220 \mathrm{~V}$ and $270 \mathrm{~V}$.

The switch voltages $\left(V_{\mathrm{M} 1}\right.$ and $\left.V_{\mathrm{M} 2}\right)$ and their switch currents $\left(I_{\mathrm{M} 1}\right.$ and $\left.I_{\mathrm{M} 2}\right)$ are shown in figures 14 and 15 respectively, which validate the zero voltage switching (ZVS) operation of both the power switches. 

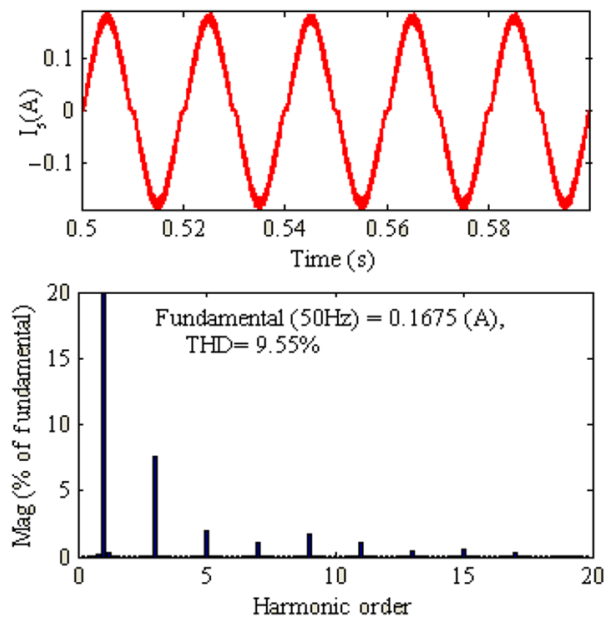

Figure 17. Input current waveform and its harmonic spectrum at ac mains voltage of $270 \mathrm{~V}$.

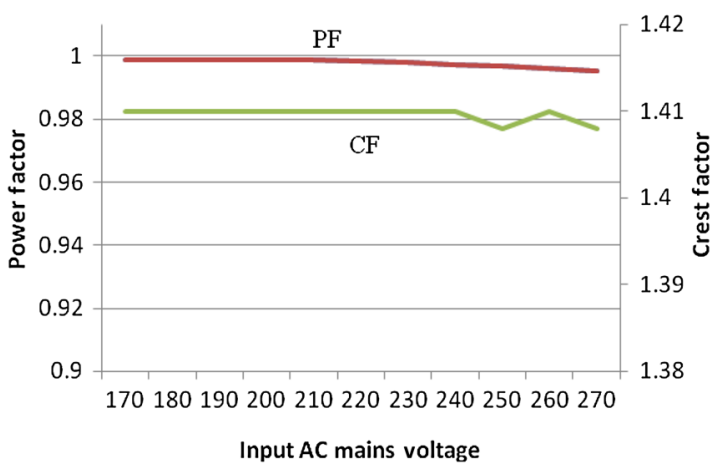

Figure 18. Power factor and crest factor with variation in ac mains voltage.

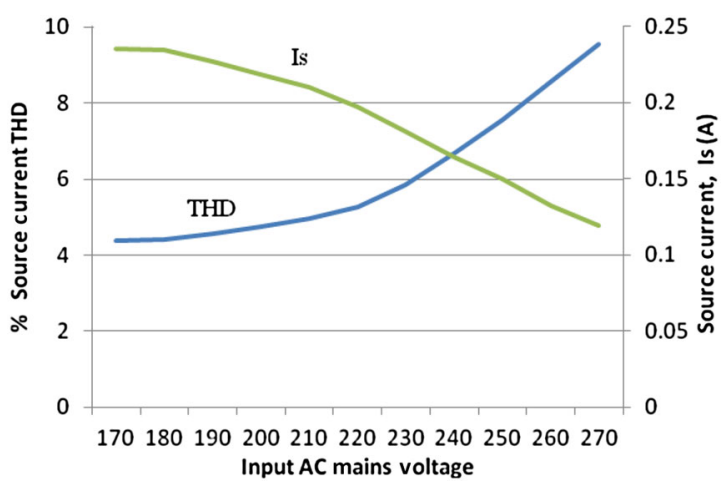

Figure 19. \% THD of source current and its magnitude with variation in ac mains voltage.

The input current waveforms along with its harmonic spectra and THD are shown in figures 16 and 17 at ac mains voltage of $170 \mathrm{~V}, 220 \mathrm{~V}$ and $270 \mathrm{~V}$.
The variation of power factor and crest factor are shown in figure 18 and the variation of \%THD of source current and its magnitude are shown in figure 19

Table 1 shows the variations of power factor $(\mathrm{PF})$, displacement power factor (DPF), \% THD of ac mains current and crest factor (CF) of PFC single-stage boost converter-based electronic ballast with a wide variation in ac mains voltage.

It has been observed that the THD of ac mains current is in between $4.34 \%$ and $9.55 \%$ for the ac mains voltage variations from $170 \mathrm{~V}$ to $270 \mathrm{~V}$. The zero voltage switching (ZVS) of switches $M_{1}$ and $M_{2}$ has been confirmed through results shown in figures 11 and 12. This has reduced the switching losses which could be significant at high switching frequency of $40 \mathrm{kHz}$.

\subsection{Experimental results}

Test results of the proposed electronic ballast are demonstrated good power quality improvement (PQI) at varying AC mains. Figures 20, 21 and 22 have shown AC mains voltage and current waveforms along with THD spectra at AC mains voltages of $170 \mathrm{~V}, 220 \mathrm{~V}$ and $270 \mathrm{~V}$ respectively. The lamp voltage and lamp current waveforms have been shown in figure 23 at AC mains voltage of $170 \mathrm{~V}$, $220 \mathrm{~V}$ and $270 \mathrm{~V}$ respectively. The measured efficiency of the proposed electronic ballast is $86.95 \%, 88.48 \%$ and $88.95 \%$ at $\mathrm{AC}$ mains voltages of $170 \mathrm{~V}, 220 \mathrm{~V}$ and $270 \mathrm{~V}$ respectively. The efficiency of the single stage electronic ballast for fluorescent lamp has reported between 80 and $85 \%$ in literature [9-13].

\section{Conclusion}

In the proposed electronic ballast, AC-DC converter with series resonant parallel loaded inverter (SRPLI) has provided an improved power quality at input $\mathrm{AC}$ mains. It has been observed that the input current meets IEC-61000-3-2 class-C requirements. High power factor single-stage electronic ballast with constant dc link voltage has been designed for the fluorescent lighting. The dc link voltage has been maintained constant, independent of changes in the input ac mains voltage. With an appropriate design of the resonant converter, the lamp current has been maintained close to the rated value. The power factor correction has been achieved by a boost converter operating in continuous conduction mode (CCM). In single-stage electronic ballast, a PFC stage and series resonant inverter stage have shared a common power switch, hence due to less number of switches as compared to two-stage approach overall switching losses are reduced considerably. Moreover, since the circuit is working at lagging power factor $\left(f_{\mathrm{r}}<f_{\mathrm{s}}\right)$, the zero voltage switching (ZVS) has been achieved in resonant inverter operation. The simulation and test results have 
Table 1. Performance parameters of proposed single stage electronic ballast.

\begin{tabular}{|c|c|c|c|c|c|c|c|c|c|}
\hline$V_{\mathrm{s}}(\mathrm{V})$ & $I_{\mathrm{s}}(\mathrm{A})$ & $V_{\mathrm{dc}}(\mathrm{V})$ & $V_{\text {lamp }}(\mathrm{V})$ & $I_{\text {lamp }}(\mathrm{A})$ & $\mathrm{PF}$ & DPF & DF & $\% \mathrm{THD}_{\mathrm{i}}$ & $\mathrm{CF}$ \\
\hline 170 & 0.2354 & 400.6 & 117.6 & 0.3016 & 0.9989 & 1 & 0.9989 & 4.38 & 1.41 \\
\hline 180 & 0.2342 & 399.8 & 120.8 & 0.3096 & 0.9989 & 1 & 0.9989 & 4.40 & 1.41 \\
\hline 190 & 0.227 & 399.5 & 123.1 & 0.3156 & 0.9989 & 1 & 0.9989 & 4.56 & 1.41 \\
\hline 200 & 0.2187 & 399 & 124.1 & 0.3181 & 0.9988 & 1 & 0.9988 & 4.74 & 1.41 \\
\hline 210 & 0.21 & 398.2 & 125.4 & 0.3216 & 0.9986 & 1 & 0.9986 & 4.97 & 1.41 \\
\hline 220 & 0.1971 & 398.3 & 124.5 & 0.3191 & 0.9985 & 1 & 0.9985 & 5.28 & 1.41 \\
\hline 230 & 0.1814 & 398.3 & 122.9 & 0.3152 & 0.9981 & 1 & 0.9981 & 5.85 & 1.41 \\
\hline 240 & 0.1644 & 398 & 119.8 & 0.3072 & 0.997 & 1 & 0.997 & 6.68 & 1.41 \\
\hline 250 & 0.1496 & 398.6 & 117 & 0.3001 & 0.9969 & 1 & 0.9969 & 7.57 & 1.408 \\
\hline 260 & 0.1324 & 399.3 & 113.5 & 0.2911 & 0.996 & 1 & 0.996 & 8.56 & 1.41 \\
\hline 270 & 0.1194 & 399.2 & 109.4 & 0.2806 & 0.9951 & 1 & 0.9951 & 9.55 & 1.408 \\
\hline
\end{tabular}
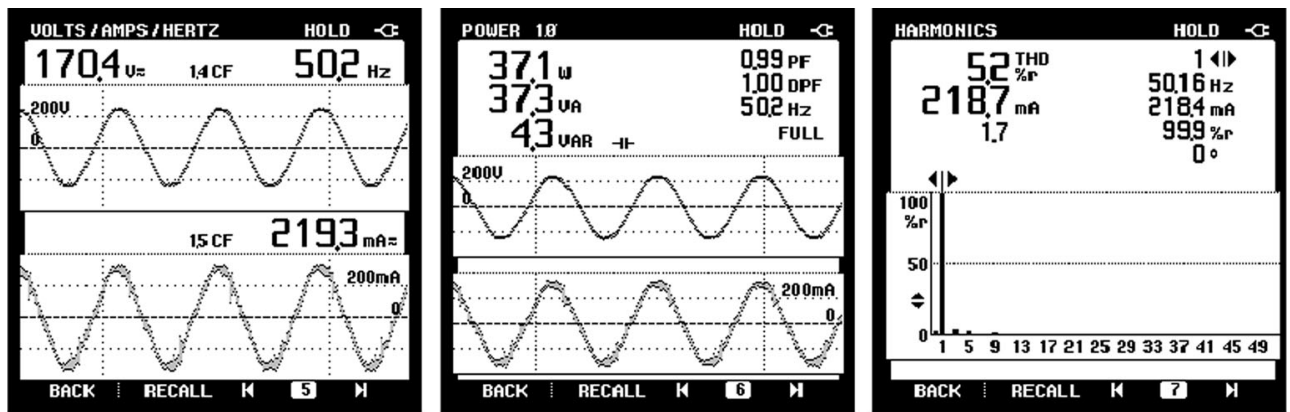

Figure 20. AC mains voltage and current waveform with THD spectrum at $170 \mathrm{~V}$ AC mains
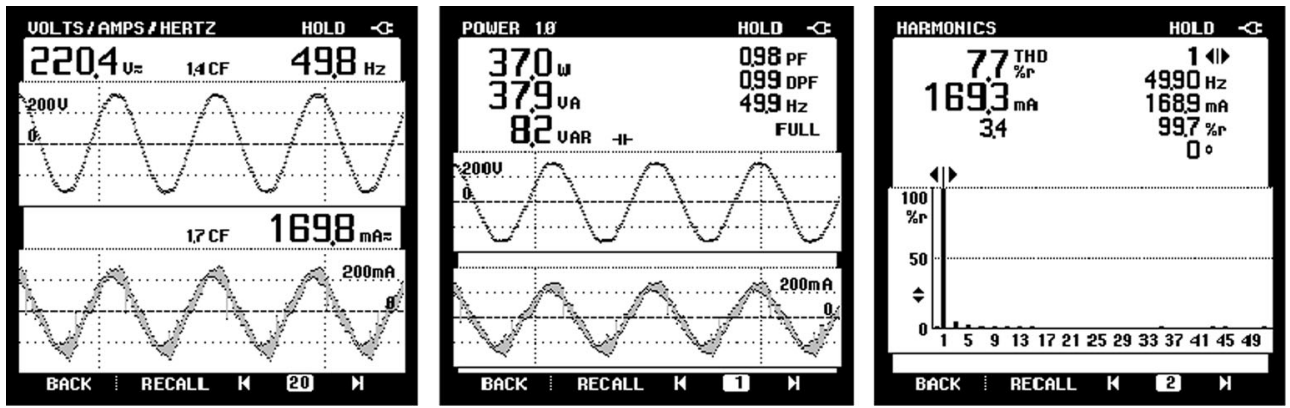

Figure 21. AC mains voltage and current waveform with THD spectrum at $220 \mathrm{~V}$ AC mains.
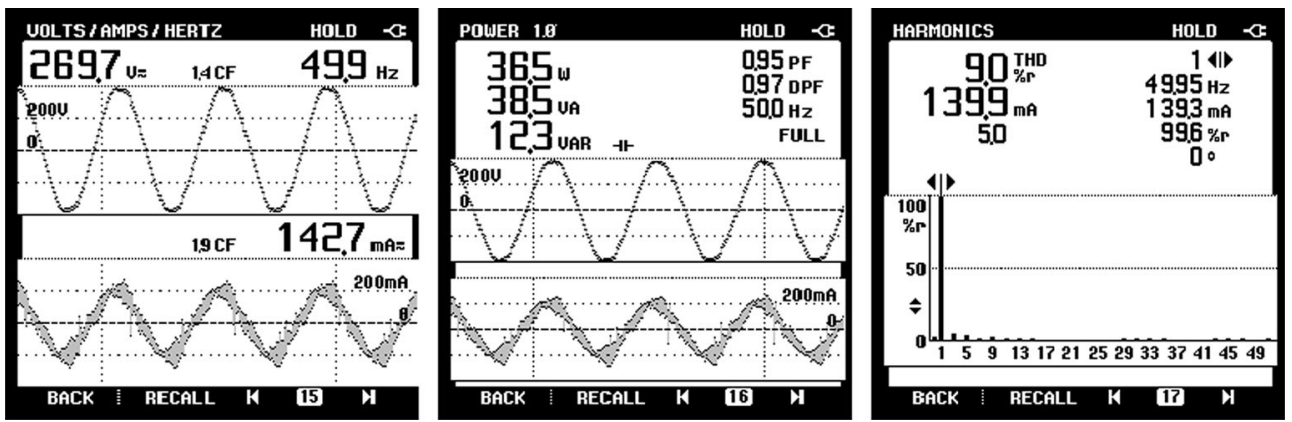

Figure 22. AC mains voltage and current waveform with THD spectrum at $270 \mathrm{~V} \mathrm{AC}$ mains. 

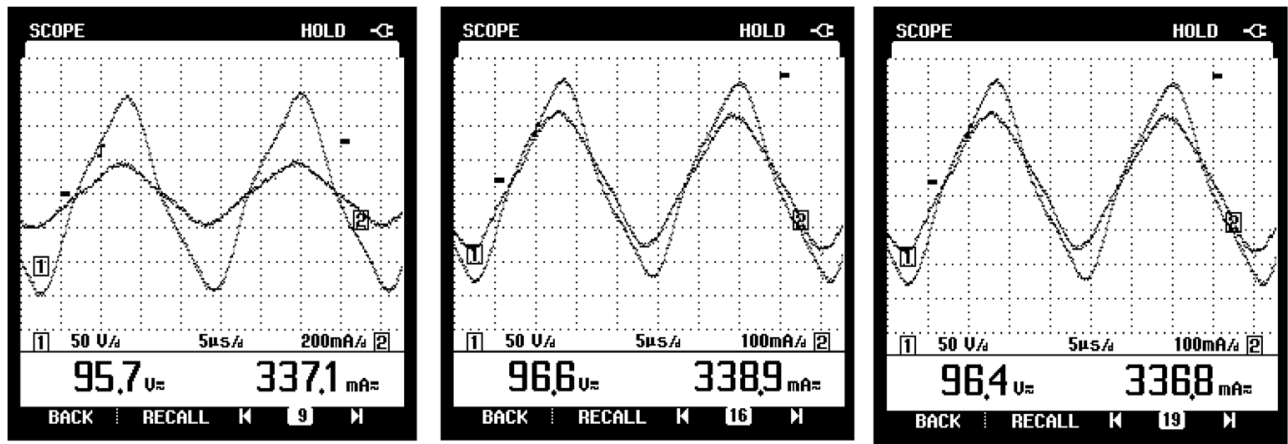

Figure 23. Lamp voltage and lamp current waveform at $170 \mathrm{~V}, 220 \mathrm{~V}$ and $270 \mathrm{AC}$ mains.

confirmed the low crest factor and high power factor of the proposed single-stage electronic ballast.

\section{Appendix}

Rated lamp power: $31 \mathrm{~W}$, rated lamp current: $0.2836 \mathrm{~A}$, rated lamp voltage: $110 \mathrm{~V}$, switching frequency $\left(f_{\mathrm{s}}\right)$ : $40 \mathrm{kHz}$, PI controller gains $\left(K_{\mathrm{p}}\right): 0.0035,\left(K_{\mathrm{i}}\right): 0.028$, Boost PFC converter components: Boost inductor $\left(L_{\mathrm{b}}\right): 40 \mathrm{mH}, \mathrm{dc}$ link capacitor $\left(C_{\mathrm{o}}\right): 30 \mu \mathrm{F}$, Resonant parameters: resonant inductor $\left(L_{\mathrm{r}}\right): 1.75 \mathrm{mH}$, dc blocking capacitor $\left(C_{\mathrm{b}}\right): 105 \mathrm{nF}$, resonant capacitor $\left(C_{\mathrm{p}}\right): 7 \mathrm{nF}$, Quality factor $\left(Q_{\mathrm{s}}\right): 2.6$, frequency ratio $(x): 0.25$.

\section{References}

[1] Kazimierczuk M K and Szaraniek W 1993 Electronic ballast for fluorescent lamps. IEEE Trans. Power Electron. 8(4): 386-395

[2] Limits for harmonic current emissions, International Electrotechnical Commission Standard, IEC 61000-3-2, 2004

[3] Chuang Y C, Moo C S, Chen H W and Lin T F 2009 A novel single-stage high-power-factor electronic ballast with boost topology for multiple fluorescent lamps. IEEE Trans. Ind. Appl. 45(1): 323-331

[4] Lee C H, Joung G B and Cho G H 1990 A unity power factor high frequency parallel resonant electronic ballast. In: Conference Record of IEEE-IAS Annual Meeting, IAS'90, pp. 1149-1156
[5] Moo C S, Chan S Y and Lee C R 1997 A single-stage high power factor electronic ballast with duty-ratio controlled series resonant inverter. In: Proceedings of IEEE Power Electronics and Drive Systems, PEDS'97, vol. 2, pp. 605-610

[6] Vieira J L F, Co M A and Zorzal L D 1995 High power factor electronic ballast based on a single power processing stage. In: Proceedings of IEEE Power Electronics Specialists Conference, PESC'95, vol. 2, pp. 687-693

[7] Brioschi R O and Vieira J L F 1997 High power factor electronic ballast with constant DC link voltage. In: Proceedings of IEEE Power Electronics Specialists Conference, PESC'97, vol. 1, pp. 80-85

[8] Co M A, Simonetti S L and Vieira J L F 1998 High-powerfactor electronic ballast operating in critical conduction mode. IEEE Trans. Power Electron. 13(1): 93-101

[9] Prado d N R, Saul B A, Moreira M C and Dalton V R L 1996 Electronic ballast with a high power factor for fluorescent lamps. In: Proceedings of IEEE Power Electronics Specialists Conference, PESC'96, pp.1215-1220

[10] Prado d N R and Saul B A 1999 A high-power-factor electronic ballast using a flyback push-pull integrated converter. IEEE Trans. Ind. Electron. 46(4): 796-802

[11] Prado d N R, Saul B A, Diego G S and Fabio B E 1997 A unity power factor electronic ballast for fluorescent lighting. In: Conference Record of IEEE-IAS Annual Meeting, IAS'97, pp. 2366-2371

[12] Prado d N R, Alysson S, Fabio B E and Tiago M 2000 Boost push-pull electronic ballast converter with high power factor for fluorescent lamps. In: Proceedings of IEEE Power Electronics Congress, pp. 182-187

[13] Tao F and Lee F C 2000 A critical conduction mode singlestage power factor correction electronic ballast. In: Proceedings of IEEE Applied Power Electronics Conference and Exposition, APEC'2000, pp. 603-609 